\title{
LITERATURA INDÍGENA E DES/COLONIZAÇÃO: LA SAGA DES BÉOTHUKSDE BERNARD ASSINIWI
}

\section{INDIGENOUS LITERATURE ANDDE/COLONIZATION: BERNARD ASSINIVIIS LA SAGA DES BÉOTHUKS}

\section{RESUMO}

Ao situar o livro de Bernard Assiniwi na interface colonização/ descolonização dos povos indígenas este ensaio focaliza três questões principais: a terra enquanto geografia habitada/ imaginada do povo beothuk; o gênero como um dos pilares desta geografia em tempos pré/pós-coloniais; a memória como estratégia de justiça e descolonização. O objetivo é problematizar como Assiniwi emancipa la memória sequestrada (Galeano) dos Beothuks por meio de uma mitopoética que revela um dos aspectos escuros do passado sangrento do Canadá: o genocídio dos Beothuks.

Palavras-chave: literatura indígena do Canadá; des/ colonização terra; gênero; memória.

\begin{abstract}
By situating Bernard Assiniwi's book at the colonization-decolonization interface of First Nations, this essay focuses on three main issues: land qua inhabited/ imagined geography of the Beothuks; gender as one of the pillars of this geography in pre/ postcolonial times; memory as a strategy of justice and decolonization. The objective is to problematize how Assiniwi emancipates la memória sequestrada (Galeano) of the Beothuks by means of a mythopoetics that reveals one of the dark aspects of Canada's bloody past: the genocide of the Beothuks.
\end{abstract}

Keywords: Native Canadian literature; de/ colonization; land; gender; memory

O objetivo do meu trabalho enquanto pesquisador das literaturas multiétnicas panamericanas é desenhar o mapa de uma geografia crítica onde o 'pós' se dilui nas ondas violentas da neocolonialidade contemporânea. Um mapa dos diversos gritos literários que ecoam nos mares e (não) lares terrestres do continente americano; gritos que traduzem uma atitude descolonizadora no sentido de problematizar e perlaborar (o durcharbeiten freudiano) o trauma da dupla brutalização de pessoas e espaços e seus efeitos que caracterizam as terras americanas. Neste processo, revelam o contingente e ambivalente entre lugar das identidades americanas enquanto espaço de perda (alienação/ subalternização, etc.) e potencialização (construção de subjetividade/ identidade: a apropriação de uma posição de sujeito). Um espaço/

Roland Walter

UFPE/CNPq. E-mail: walter_roland@hotmail.com; rolandgwalter@yahoo.com 
tempo multidimensional e fractal cuja realidade intersticial é caracterizada por um passado reimaginado que hifeniza o presente linear numa performance espiral em direção a um futuro utopicamente melhor ou alternativamente diferente no sentido blochiano. Trata-se, portanto, de um mapa que traça esta dupla brutalização com a intenção de dar respostas tentativas à pergunta 'Quem fomos e quem somos nas Américas, ou seja, quais as significações das Américas, de sua "unidade múltipla”, sua multiplicidade do um" como diria Edgar Morin (2001, p.70). Faço isto enquanto outsider étnico-racial que olha/fala/escreve sobre o/a outro/a e como insider profissional que tenta comunicar com o/a outro/a de dentro dos textos para fora, sendo consciente deste complexo entre lugar da minha fala/ escrita. Um lugar complexo caracterizado pela seguinte dupla escrita: a) a colonização/descolonização enquanto paradigma de ocupar, inscrever /desterritorializar, re (des)escrever/ imaginar; b) a colonização/ descolonização enquanto processos implementados em redes de relações pessoais de práticas/ imaginações do dia-a-dia. A complexidade ainda aumenta se consideramos o que Derrida (1976, p. 93) chama de "thought", pensamento qua "blank part of the text”, esse espaço branco do texto que é inacessível mas que vibra na interface dito/ não dito, texto/ subtexto. Como lidar com/ acessar este falar na fala textual - este skaz do qual fala Bakhtin ${ }^{1}$ - na zona de contato transfronteriza (Pratt, 1997; Saldívar, 1997) onde diferentes culturas, ou melhor, elementos destas, dançam aos ritmos sincópicos das relações de poder?

É a palavra que recupera um mundo de referências mediante a memória. Este mundo de referências, ao depositar a consciência histórica como sedimento, (re) constitui a identidade individual e coletiva num processo histórico. Desta forma, a literatura recria o ethos e a cosmovisão cultural e revela o que a historiografia oficial distorce e/ou esconde. A literatura ameríndia contemporânea nas Américas é um produto da relação colonial entre europeus e ameríndios. "Cada palavra escrita em inglês”, observa Louis Owens (1998, p. 6) com respeito à literatura ameríndia dos Estados Unidos, "representa um tipo de colaboração e uma reorientação consciente ou inconsciente - do mundo paradigmático da tradição oral para a realidade sintagmática da linguagem escrita”. ${ }^{2}$ Este lugar entre epistemes culturais que implica a dessacralização do material sagrado que move do âmbito oral, coletivo, à arte secular escrita, individual é, de certa forma, um espelho heterotópico da entre condição dos povos indígenas nas Américas. A marginalização das Primeiras Nações em reservas sem soberania enquanto símbolo geográfico-ideológico da violência do regime (neo)colonial significa também uma desterritorialização identitária e epistêmica que continua enquanto colonialidade até hoje. A brutalização dos ameríndios é um genocídio que se iniciou com a chegada dos colonizadores europeus e ainda não terminou.

Nas Américas a brutalização das pessoas é ligada à brutalização do espaço e estas brutalizações são enraizadas no passado: o genocídio das nações indígenas, a

1 Mikhail Bakhtin utiliza 'skaz', uma palavra russa, para indicar um discurso oral trabalhando dentro de e agindo sobre o discurso escrito. Ver Bakhtin (1984, p. 190-193).

2 As traduções neste ensaio são de minha autoria. 
escravização dos africanos e afrodescendentes e o sistema de plantação e as várias formas de exploração da natureza, entre outros, caracterizaram as diferentes fases e processos de colonização e ainda continuam ter um impacto sobre o pensamento e o agir das pessoas não somente em termos de como as pessoas se relacionam e tratam os diversos outros, mas de como as imagens destes eventos traumáticos perseguem os pensamentos e agenciamentos. A violência física, epistêmica e ecológica do continente americano constitui uma rede gerada por e baseada no que Anibal Quijano tematizou como colonialidad del poder. ${ }^{3}$

Neste processo, a violência epistêmica, determinando sujeitos em termos absolutistas, subalternizantes, espelha e trabalha para racionalizar e naturalizar a violência material, física exercida sobre os corpos de todas as espécies bióticas. Violência esta que estabelece zonas de barbárie baseadas na negação sistemática de direitos humanos e posse de terra delineado em vários acordos internacionais, como por exemplo The Universal Declaration of Human Rights, The United Nations Declaration on the Rights of Indigenous Peoples and the FAO Voluntary Guidelines On the Governance of Tenure, entre outros. Dito de outra forma, nas palavras de Francisco Alarcón (1992, p. 34), as Américas continuam ser "invadidas, ocupadas, branqueadas, fragmentadas, higienizadas, suprimidas e/ ou ignoradas".

Segundo Annette Jaimes (1992, p. 7; enfase minha), "a taxa do extermínio que os povos indígenas dos Estados Unidos sofreram é muito maior que aquela vivenciada pelos judeus da Europa sob o regime nazista" e "representa uma dimensão e um âmbito de genocídio sem paralelo na historia registrada"; genocídio este que continua até o presente e se caracteriza por marginalização, subalternização, desumanização, violência física e epistêmica. Trata-se de um contínuo deslocamento deliberado das Primeiras Nações de suas terras e culturas - roubadas, delimitadas, invadidas, incendiadas, proibidas, distorcidas - em nome de um progresso capitalistaimperialista baseado no saque das matérias primas com o objetivo de maximizar lucro.

Mesmo sendo um produto da colonização, como frisei antes, a literatura indígena contribui para a descolonização do que Eduardo Galeano chamou "la mémoire brisée" (2005, p. 93) e "la memoria secuestrada de toda América" (1982, p. 12) dentro de uma "não historia” (GLISSANT, 1992, p. 62), ou seja, uma história esquizofrenicamente caracterizada por lacunas e rupturas com base na violação dos direitos humanos, vegetais e animais. Glissant (1997, p. 150-151) em sua "estética da terra" enquanto caminho de descolonização das relações interbióticas, enfatiza a importância do passado para o presente, ou melhor, de um passado colonizador no presente pós/ neocolonial ao argumentar e revelar que a terra pan-americana e os seus habitantes são saturados por traumas de conquista - o "tempo torturado" e

3 Em resumo, a argumentação de Quijano focaliza a categorização hierárquica das regiões e populações mundiais pela hegemonia ocidental (raça; gênero, trabalho; meios de produção); o papel da mídia, da ideologia, do sistema educacional e do Estado no estabelecimento desta hierarquia dentro de cada nação e entre nações e os fluxos de capital e de seres humanos determinados e controlados pelas relações de poder. 
"espaço transferido" do continente americano provocando nos escritores a busca por duração temporal e espacial. Em seguida, gostaria de problematizar alguns aspectos deste espejo trizado ${ }^{4}$ no livro La Saga des Béothuks (1996) de Bernard Assiniwi, indígena canadense da nação dos Cree.

La Saga des Béothuks delineia as mudanças dramáticas na vida dos Beothuks (um povo indígena com base na ilha de Terra Nova, Canadá), com a chegada de diversos intrusos/ colonizadores entre os anos 1000 e 1829, quando morre a última representante deste povo. A saga, portanto, baseada em fatos históricos (o autor é historiador), conta a vida deste povo antes e depois da chegada dos vikings, franceses e ingleses até a sua exterminação. De século a século, a narração revela detalhes da alienação forçada dos Beothuks de sua cultura, língua e terra, ou seja, de sua identidade e maneira de viver. Dos inúmeros detalhes ficcionalizados nos 514 páginas do romance, gostaria de focalizar primeiro o que, devido a sua atualidade enquanto questão não resolvida para as nações indígenas contemporâneas me parece ser um tema-chave da colonização e seus efeitos: a relação com a terra enquanto espaço habitado por diversas espécies, o que Edward Soja (1989, p. 7) chama a "geografia afetiva", ou seja, "a concretização das relações sociais embutidas na espacialidade". Em seguida, seria abordada a questão de gênero enquanto um dos vários vetores socioculturais efetivando esta afetividade da geografia representada no romance historiográfico de Assiniwi. Estes dois temas, a terra e o gênero, serão entrelaçados por reflexões sobre o papel da memória e seu objetivo nesse romance, a saber: erigir um monumento escrito à nação dos Beothuks - um monumento mnemônico que revela e problematiza a barbárie da colonização das terras 'novas' que mais tarde integrarariam o Canadá.

Enquanto que os Beothuks viviam em sintonia com a terra e o mar (eram caçadores e pescadores), sua base de subsistência, para os ingleses e franceses a conquista deste espaço era uma chance de aumentar os lucros, por exemplo, com a venda da pele de animais e o desmatamento pelo uso e venda da madeira. Ao colocar os Beothuks num nível civilizatório inferior de selvagens sem direito a vida, se deram a licença de matar não somente os animais e destruir a vegetação, como também os nativos que viviam neste ambiente. Reduzidos a objetos pelos colonizadores, os homens beothuks foram assassinados e as mulheres violadas, assassinadas ou tratadas como propriedade comparável a gado. Da perspectiva do marinheiro francês Jean Le Guellec que se integra à nação dos Beothuks por volta de 1534, a voz narrativa compara a visão colonialista com o ser-estar beothuk na terra compartilhada, mas não possuída no sentido capitalista. Ele se da conta que o indivíduo na sociedade beothuk tem um grau de autonomia que ele "nunca tinha conhecido na sua nação".

4 Joaquín Brunner (1988, p.15) descreve com este termo a realidade fractal da América Latina desde a chegada dos europeus.

5 Em 1928, José Carlos Mariátegui, nos seus 7 ensayos de interpretación de la realidad peruana, argumentou que a "cuestión indígena" tem seus raizes no "régimen de propiedad de la tierra" (p. 153). Em geral, políticas neoliberais combinadas com as crises de dívida na América Latina fortaleceram os sistemas de latifúndios e promoveram a expropriação da terra em nome de exportação, mineração e turismo, entre outros. 
Uma liberdade que nasce do saber adquirido da experiência dentro de um espaço percebido como objeto de sobrevivência $e$ sujeito/ agente que transmite uma sabedoria social e cultural: "Ele compreendeu que o saber verdadeiro surgiu do meio ambiente e não da escola. Os franceses tinham adotado o alfabeto para poder ler e escrever. Ao mesmo tempo, porém, mataram o conhecimento que as pessoas tinham do seu meio ambiente. Não sabiam mais ler a natureza e os elementos" (ASSINIWI, 1996, p. 279-280). O que Jean Le Guellec entende na sua convivência com os Beothuks e o que a voz narrativa delineia de maneira detalhada ao longo da narrativa, ou seja, a importância da terra enquanto base de sustentação tanto física quanto espiritual, foi expresso pela escritora lakota Leslie Marmon Silko da seguinte forma: "a paisagem ressoa a dimensão espiritual-mítica do mundo pueblo mesmo hoje”; "características e pontos de referência geográficos que são mencionados nas narrativas existem para propósitos rituais" (1997, p. 36-37); ou seja, têm importância para recriar o caminho do passado ao presente, entender-se enquanto coletividade via processo de imaginação. Com relação à oralização da memória, Silko observa que ouvindo as histórias ela é capaz de "visualizar-se como sendo situada dentro da história contada, dentro da paisagem”. Portanto, "a identidade foi ligada com o território, a paisagem, que muitas vezes teve um papel significante na história ou no desfecho de um conflito” (1997, p.43).

Além disso, reconhece o marinheiro, a sociedade beothuk é caracterizada por uma estratificação não hierárquica e patriarcal sem "nobres [...] ricos [...] mestres [...] servos" e as mulheres "participaram na vida política desde há mais tempo que a memória; e a memória era longa como a eternidade”. A sabedoria, o conhecimento, aprende o francês, reside na experiência vivida e na transmissão da memória dos mortos aos vivos e àqueles que nascerão. Assim "sobrevive um povo, uma nação" (ASSINIWI, 1996, p. 281).

Segundo Michel Foucault, a memória é um fator importante da luta cultural de povos subalternizados. É um meio de reconstruir a identidade dentro de um processo de reescrita historiográfica; uma contramemória que Foucault (1980, p. 81) chama de “insurreição do saber subjugado”. Se para Charles Taylor (1989, p. 28) a memória possibilita o conhecimento da posição de sujeito e, nesse processo, constitui um "espaço moral, um espaço no qual questões sobre o que é bom ou mal são levantadas, o que vale a pena fazer ou não, o que faz sentido e tem importância para alguém e o que é trivial e secundário", então argumento, esta "insurreição" mnemônica via palavra é uma atitude descolonizadora que recria o dinamismo cultural alienado pela colonialidad del poder. Neste processo retificador a palavra descolonializadora rompe o que Silvia Rivera Cusicanqui (2010) problematiza como o encobrimento enquanto "función para las palabras en el colonialismo"6 e recria um mundo de referências necessário para a (re)constituição da identidade mediante a memória.

Ao declarar que a memória desta nação indígena não morreu, mas vive nas memórias de outras pessoas, outras nações autóctones, Bernard Assiniwi (1996, p.

6 A ordem das palavras na frase foi alterada pelo autor deste artigo. 
281) assinala a importância da memória coletiva que Marianne Hirsch (1999) define como pós-memória daquelas gerações subsequentes que não viveram os eventos traumáticos, mas os conhecem somente por meio de "estórias e imagens com as quais cresceram” e pelos efeitos no presente.7 Com o termo 'pós-memória' e sua aplicação à literatura indígena, porém, surgem pelo menos dois problemas. Primeiro, igual à discussão do prefixo 'pós' no termo 'pós-colonial', a questão do significado do prefixo; ou seja, como pode existir um 'depois' da memória se esta continua persistir ? Neste sentido, mesmo com a explicação de Hirsch, resta uma ambiguidade e/ ou mal-estar com o termo. Segundo, discordo com Hirsch quando ela declara que a pós-memória "não é uma posição identitária”. Se a cultura é um efeito mnemónico - codificada pela memória imbuída de ideologia e valores — que mediante a linguagem determina o nosso etos e cosmovisão, ou seja, a maneira como pensamos e interpretamos não somente o mundo, como também a nosso posição de sujeito no mundo, então o processo de lembrar e esquecer tem um impacto sobre a nossa posição identitária. Além desses aspectos inquietantes, a relação entre a pós-memória de Hirsch e a memória heteropática de Silverman é outro ponto que deve ser examinado com atenção: onde se encontra o limite entre identificação empática enquanto meio/ atitude descolonial e apropriação/ neocolonização étnico-cultural que inventa mais uma vez o/a Outro/a? Ademais, com relação à literatura indígena das Américas, alego que o termo de Hirsch não abrange a ligação entre diferentes espécies. Neste sentido, acho mais propício utilizar o termo "memória inter/transbiótica" (WALTER, 2016): uma memória que liga o mundo vegetal, animal e humano num espaço que é tanto objeto de percepção quanto médium que transmite um particular saber cultural e social: um milieu de mémoire, nas palavras de Pierre Nora; ou como articulou Hinma-too-yah-lat-kekht (Chief Joseph) em maio de 1877, the earth and myself are of one mind - a terra e eu somos da mesma mente.

Um dos pilares desta geografia afetiva que liga as vibrações ritmicasrizomáticas da terra e suas espécies enquanto (mi)lieu vivido e imaginado - uma estética de terra que aproxima imaginários culturais multiétnicos numa relação

\footnotetext{
7 Para Hirsch (1999, p.8, 9) a "pós-memória é uma forma poderosa de memória precisamente porque a conexão dela com seu objeto ou fonte é mediada não por meio de recordação, mas por projeção, investimento e criação". Ela "caracteriza a experiência daqueles [...] cujas próprias estórias tardias são deslocadas pelas histórias das gerações previas, moldadas por eventos traumáticos que eles podem nem compreender nem recriar". Essa pós-memória, segundo Hirsch, "não é uma posição identitária, mas um espaço de remembrance em geral mais disponível mediante atos de rememorização, identificação e projeção cultural e pública e não meramente individual e pessoal”. Como tal, este tipo de memória caracteriza-se pela adoção das "experiências traumáticas — e assim também das memórias — dos outros como se fossem as próprias, ou mais precisamente, como experiências que se podiam ter tido e pela inscrição destas na sua própria história de vida”. Para Hirsch, a pós-memória abrange relações entre gerações do mesmo grupo ou entre grupos étnico-culturais e implica uma relação ética com pessoas oprimidas e perseguidas. Hirsch baseia sua argumentação nas ideias de Silverman (1996, p. 185) que chamou este processo "memória heteropática" e "identificação": por meio de "memórias discursivamente implantadas" a pessoa pode "participar nos desejos, lutas e sofrimentos do outro"; ou seja, mesmo sendo distante pode identificar-se com o outro sem, porém, interiorizá-lo, sem se perder no outro, mas sair de sim em direção aos outros.
} 
descolonizadora da mapa cognitiva traçado pelo discurso hegemônico do Ocidente — é a questão do gênero. Deixem-me introduzir esse assunto com a seguinte citação:

Além das atividades comunitárias da secagem e da defumação da carne e do peixe, as mulheres discutiram firmemente os costumes e a tradição. Quando não concordaram com um ponto consultaram o pajé. E caso que o detentor da tradição não sabia, porque nunca se tinha debruçado sobre a questão, as mulheres decidiram entre elas o que fazer. Em seguida, encontraram-se com o pajé para dizê-lo que tal ou tal hábito fazia parte integrante da tradição a partir de agora porque as mulheres tinham tomado esta decisão. Como as mulheres estavam condenadas a ficar sozinhas no acampamento enquanto os homens exploravam o entorno, elas exigiram o direito de integrar o conselho da nação. (...) Esta nova atitude das mulheres não desagradou o ancião esperto que entendeu muito bem a legitimidade deste interesse. Se as mulheres foram levadas a ter um papel tão importante no desenvolvimento da nação, elas deviam necessariamente articular a sua palavra com relação ao seu destino. Se elas aceitaram ter filhos para aumentar a população e permitir a ocupação de todo o território, então deveriam fazer parte das decisões. De outra forma não seria justo (ASSINIWI, 1996, p.192-193).

Este trecho citado nos indica primeiro que as questões do colonialismo, como as da colonialidad del poder, são, como argumenta Maria Lugones (2008), profundamente engendrizadas. A colonização - invasão, ocupação e exploração de uma terra nullius - afeta o mundo vegetal, animal e humano de um determinado locus enquanto rede de efeitos nocivos interligados. $\mathrm{O}$ fato que as ondas de intrusos aumentaram continuamente entre 1000 e 1800 , tem um forte impacto sobre a convivência dos Beothuks enquanto comunidade social e culturalmente organizada em relação com seu ambiente e outros povos autóctones. Segundo Assiniwi, uma das mudanças devido à necessidade de defender o território contra os colonizadores franceses e ingleses, especialmente a partir do momento que começaram a erigir os primeiros fortes e vilas e desta forma restringir as áreas de caça e pesca necessárias à sobrevivência dos Beothuks, era a participação das mulheres em todas as esferas da estruturação social e cultural das comunidades. Assim, quem das mulheres tinha o dom de caçar, pescar, guerrear, etc. podia fazê-lo. Gênero, nesta representação do cenário colonial, é definido por habilidades físicas e espirituais.

Ao focalizar as relações sexuais dos Beothuks, Assiniwi enfatiza que esta igualdade entre homens e mulheres não existia sempre. Segundo a voz narrativa, oscilando entre a omnisciência da terceira pessoa assumindo as perspectivas masculina e feminina, em tempos pré-coloniais o homem podia escolher mais que uma esposa, selecionando-a entre as irmãs da primeira para evitar possíveis disputas. Anin, o último fundador e chefe de um novo clã beothuk pré-colonial, 
deixa bem claro que o costume dá ao chefe do clã o direito de escolher uma segunda mulher quando quiser (ASSINIWI, 1996, p. 128). Por volta do ano 1000, com os cada vez mais frequentes ataques dos vikings, inicia-se a assimilação de estrangeiros na nação beothuk - no romance são uma mulher e um homem escocês que eram escravos dos vikings, e duas islandesas ${ }^{8}$. No caso específico, Woasut, a esposa de Anin, inicialmente sente raiva pela decisão de seu marido ter relações sexuais com uma mulher estrangeira salva pelos dois, pensando que “... ter várias mulheres era uma vantagem para o homem e uma maneira de preservar o bom humor dele. Para a mulher, porém, isso era uma fonte de aborrecimento e inveja. Uma fonte de insatisfação, também, e mais uma razão de ser mal humorada" (ASSINIWI, 1996, p.121). A harmonia é restabelecida no dia-a-dia de luta pela sobrevivência e a amizade e atração física que se desenvolve entre ela, seu marido e mais três mulheres do novo clã. Woasut, a única sobrevivente de um massacre, agora, "não sentia mais rancor ... . Ela tinha a impressão de novamente fazer parte de uma família. As três mulheres não lhe apareciam mais como rivais mas como irmãs com as quais podia trocar (ideias) aprender e compreender a vida" (ASSINIWI, 1996, p. 134). Em trecho mais adiante, quando Gudruide entra sorrindo na habitação e vê as duas outras esposas de Anin "nuas, ainda entrelaçadas", o narrador reitera que estas "relações do clã" são caracterizadas por "solidarité"; uma solidariedade unindo "homens e mulheres que tinham apreendidos a viver juntos sem nenhuma inveja" (ASSINIWI, 1996, p. 159). A liberdade sexual que Assiniwi imagina enquanto característica das relações de gênero nos rastros mnemônicos do passado beothuk, portanto, inclui relações homoefetivas (de mulheres) e heterossexuais dentro de um modo de vida cujo objetivo principal era a sobrevivência - a estabilidade entre a taxa dos nascimentos e das mortes como clã dos Beothuks na época que marca o início da colonização.

Com relação à argumentação de Paula Gunn Allen (1992) que a colonização da terra, dos hábitos e maneira de viver e pensar das primeiras nações e os efeitos desta até a contemporaneidade tenham implicado na destruição de sistemas matriarcais indígenas em algumas nações ${ }^{9}$, Bernard Assiniwi suplementa, semelhante ao caso das mulheres maya-quiché na luta contra os espanhóis em La mujer habitada de Gioconda Belli (o caso de Itzá), que as mulheres beothuk se 'emanciparam' por necessidade de sobrevivência durante a guerra de resistência contra os colonizadores. Em tempos de luta contra os invasores, especialmente a partir dos anos 1500 quando a taxa da mortalidade masculina aumentou constantemente, a emancipação feminina aconteceu enquanto prática social necessária e estratégia de resistência com o objetivo de garantir a sobrevivência da nação beothuk.

8 Com esta inserção dos primeiros estrangeiros no povo beothuk inicia-se o processo transcultural do intercâmbio dos costumes. Em geral, os estrangeiros adaptam-se aos costumes dos Beothuks devido à experiência e sabedoria destes de (sobre)viver na sua terra; costumes aprimorados por alguns ferramentos trazidos pelos estrangeiros. Esta aculturação torna-se uma transculturação pelo fato das mulheres estrangeiras introduzirem relações homoafetivas na convivência dos Beothuks.

9 Ela fala da "mudança dos sistemas ginocêntrico-igualitários com base em rituais para sistemas falocêntricos, hierárquicos" (p. 38). 
Ao retomar as noções de 'memória', 'tempo' e 'espaço', gostaria de observar que a atividade mitopoética de Bernard Assiniwi, em busca de duração temporal, espacial e identitária, preenche o "tempo torturado" e "espaço transferido", no sentido glissantiano, os traços mnemônicos traumáticos destes, com emoção e imaginação para erigir um monumento textual dos Beothuks. É uma atividade mitopoética de resistência no sentido de descolonizar um discurso hegemônico que condena a existência/ experiência de alguns ao silêncio; ato este que equivale a uma não existência. Se para Toni Morrison em A Mercy (2008), os colonos europeus, os escravizados negros e a população das Primeiras Nações se tornaram 'orfãos' neste embate colonial, então para Bernard Assiniwi a violenta história do Canadá demonstra não somente os detalhes cruéis da orfanização dos Beothuks como também que há fósseis étnico-culturais deslembrados do passado que nutrem o Canadá multicultural de hoje. ${ }^{10}$ Destarte, Bernard Assiniwi, entre outros escritores indígenas, une-se em diferença a muitos escritores afrodescendentes do Canadá em criticar um país que abriga alguns de seus cidadãos e orfaniza outros desde o passado ao presente (WALTER, 2009, p. 55). Juntos com outros escritores e escritoras panamericanos/as contribuem para tecer um mapa de geografia critica do continente cujas contramemórias e implícitas estetizações de diversos tipos de violência revelam a dupla e inter-relacionada brutalização dos seres humanos e do seu (meio) ambiente; brutalização esta que constitui de diversas maneiras o inconsciente sociocultural e ecológico da experiência pan-americana - os fantasmas destes holocaustos recalcados que voltam em resposta à Verleugnung (negação) fazendo sentir sua presença tanto no nível da enunciação quanto no da experiência vivida e imaginada.

\section{Referências Bibliográficas}

ALARCÓN, Francisco (1992). "Reclaiming Ourselves, Reclaiming America". In: GONZÁlEZ, Ray (ed.) Without Discovery: A Native Response to Columbus. Seattle, WA: Broken Moon Press. p. 29-38.

ALLEN, Paula Gunn. The Sacred Hoop. Recovering the Feminine in American Indian Traditions. Boston, Beacon Press, 1992

ASSINIWI, Bernard (1996). La Saga des Béothuks. Monréal: Leméac.

BAKHTIN, Mikhail (1984). Problems of Dostoevsky's Poetics. Ed. Caryl Emerson. Minneapolis: University of Minnesota Press.

BELLI, Gioconda. (1996), La Mujer Habitada. Buenos Aires: Emecé Editores.

10 Parafraseando Wilson Harris (1981, p. 90), poeta e pensador caribenho, que fala “(d)o fóssil vivo de culturas sepultadas" nas Américas. 
BRUNNER, José Joaquín (1988). Un espejo trizado. Ensayos sobre cultura y política culturales. Santiago: FLACSO,

CHIEF Joseph (1971). In: MCLUHAN, T.C (ed.). Touch the Earth: A Self-Portrait of Indian Existence. New York: Simon and Schuster. p. 54.

CUSICANQUI, Silvia R. (2010) Ch’ixinakax utxiwa. Una reflexión sobre prácticas y discursos descolonizadores. Buenos Aires: Tinta Limón.

DERRIDA, Jaques (1976). Of Grammatology. Trans. Gayatri Ch. Spivak. Baltimore/ London: The Johns Hopkins University Press.

FOUCAULT, Michel (1972). Power/Knowledge. Ed. Colin Gordon. New York: Pantheon Books,

GALEANO, Eduardo (2005). “Ce passé qui vit en nous”. Manière de voir, 82: p. 91-93, août-septembre.

GALEANO, Eduardo (1982). Memoria del fuego 1. Los nacimientos. Madrid: Siglo XXI.

GLISSANT, Édouard (1992). Caribbean Discourse. Charlottesville: University Press of Virginia.

GLISSANT, Édouard (1997). Poetics of Relation. Ann Arbor: The University of Michigan Press.

HARRIS, Wilson (1981). Explorations: A Selection of Talks and Articles 1966-1981. Mundelstrap: Dangeroo Press.

HIRSCH, Marianne (1999). "Projected Memory: Holocaust Photographs in Personal and Public Fantasy." In: BAL, Mieke; CREWE, Jonathan; SPITZER, Leo (eds.). Acts of Memory. Cultural Recall in the Present. Hanover/London: New England University Press. p. 3-23.

JAIMES, Annette, ed. (1992). The State of Native America: Genocide, Colonization, and Resistance. Boston: South End Press.

LUGONES, María( 2008). “Colonialidad y Género”. Tabula Rasa. Bogotá - Colombia, 9: p.73-101, julio-diciembre.

MARIÁTEGUI, José Carlos (2009). 7 ensayos de interpretación de la realidad peruana. Buenos Aires, Capital Intelectual. 
MORIN, Edgar (2001). La methode, vol. 5. Paris: Ed. Seuil.

MORRISON, Toni (2008). A Mercy. New York: Alfred A. Knopf.

NORA, Pierre (1989). "Between Memory and History: Les Lieux de Mémoire". Representations, 26: p. 7-25, Spring.

OWENS, Louis (1992). Other Destinies: Understanding the American Indian Novel. Norman: University of Oklahoma Press.

PRATT, Mary Louise (1997). Ojos Imperiales: Literatura de Viajes y Transculturación. Buenos Aires: Ed. Universidad Nacional de Quilmes.

QUIJANO, Anibal (1997). “Colonialidad del poder, cultura y conocimiento en América Latina.” Anuario Mariateguiano, 9. 9: p. 113-120.

SALDIVAR, José D. (1997). Border Matters. Remapping American Cultural Studies. Berkeley: University of California Press.

SILKO, Leslie M. (1977). Ceremony. New York: Penguin.

SILVERMAN, Kaja (1996). The Threshold of the Visible World. New York: Routledge.

SOJA, Edward (1989). Postmodern Geographies: The Reassertion of Space in Critical Social Theory. London: Verso.

TAYLOR, Charles (1989). Sources of the Self: The Making of the Modern Identity. Cambridge: Harvard UP.

WALTER, Roland (2009). "Identities on the Move: Of Cultural Fissures and Fusions in Black Canadian Literature". Canadian Review of Comparative Literature/ Revue Canadienne de Littérature Comparée 36.1: p. 42-59.

WALTER, Roland (2016). "Inter/ Transbiotic Memory Traces: Transculturation and Decolonization in Inter-American Literature”. Fiar, 9.2: p. 34-54, September. 